\title{
Balancing the immune response in the brain: IL-10 and its regulation
}

\author{
Diogo Lobo-Silva ${ }^{1,2}$, Guilhermina M. Carriche ${ }^{3,4}$, A. Gil Castro ${ }^{1,2}$, Susana Roque ${ }^{1,2}$ and Margarida Saraiva $a^{3,4^{*}}$ (D)
}

\begin{abstract}
Background: The inflammatory response is critical to fight insults, such as pathogen invasion or tissue damage, but if not resolved often becomes detrimental to the host. A growing body of evidence places non-resolved inflammation at the core of various pathologies, from cancer to neurodegenerative diseases. It is therefore not surprising that the immune system has evolved several regulatory mechanisms to achieve maximum protection in the absence of pathology.

Main body: The production of the anti-inflammatory cytokine interleukin (IL)-10 is one of the most important mechanisms evolved by many immune cells to counteract damage driven by excessive inflammation. Innate immune cells of the central nervous system, notably microglia, are no exception and produce IL-10 downstream of pattern recognition receptors activation. However, whereas the molecular mechanisms regulating IL-10 expression by innate and acquired immune cells of the periphery have been extensively addressed, our knowledge on the modulation of IL-10 expression by central nervous cells is much scattered. This review addresses the current understanding on the molecular mechanisms regulating IL-10 expression by innate immune cells of the brain and the implications of IL-10 modulation in neurodegenerative disorders.

Conclusion: The regulation of IL-10 production by central nervous cells remains a challenging field. Answering the many remaining outstanding questions will contribute to the design of targeted approaches aiming at controlling deleterious inflammation in the brain.
\end{abstract}

Keywords: Interleukin-10, Pattern recognition receptors, Glial cells, Molecular regulation, Neurodegeneration

\section{Background}

The process of microglial cells and astrocyte activation is an essential component of the inflammatory response against pathogens and damage in the central nervous system (CNS). However, if not regulated, this process leads to a series of events that culminate in the damage of healthy nearby cells. In this context, the tight regulation of immune cell activation is of utmost importance, to avoid propagation of neurodegenerative processes. Interleukin (IL)-10, an anti-inflammatory cytokine, prevents immunopathology in several diseases and disease models, both in the periphery and in the CNS. Here, we review the current knowledge on the molecular mechanisms regulating IL-10

\footnotetext{
* Correspondence: margarida.saraiva@ibmc.up.pt

${ }^{3}$ i3S - Instituto de Investigação e Inovação em Saúde, Universidade do Porto, Rua Alfredo Allen, 208, 4200-135 Porto, Portugal

${ }^{4}$ IBMC - Instituto de Biologia Molecular e Celular, Universidade do Porto,

Porto, Portugal

Full list of author information is available at the end of the article
}

production by microglial cells and astrocytes and how that balances the immune response in the CNS.

\section{Introduction}

Interleukin (IL)-10 was identified over two decades ago [1] and is to date the most studied suppressive molecule of the immune system. IL-10 plays a critical role in preventing inflammatory and autoimmune pathologies by limiting the immune response to pathogens and microbial flora [2]. Mouse models of IL-10 deficiency develop inflammatory bowel disease upon colonization of the gut with particular microorganisms [3], whereas in humans, genetic studies have confirmed the essential role of IL-10 in preventing deleterious inflammation in the gut [4]. However, the role of IL-10 clearly exceeds the regulation of intestinal inflammation, as a function for this molecule has been also described in chronic infection, tumour surveillance and neurodegenerative disorders [5-7]. 
IL-10 production was originally ascribed to CD4+ T helper type 2 (Th2) cells [1]. Since then, IL-10 production has been described for a wide variety of immune cells, including Th1 and regulatory T cells, CD8+ T cells, $B$ cells, macrophages, dendritic cells, neutrophils and eosinophils [6]. Notably, some non-haematopoietic cells, as epithelial cells, are also able to produce IL-10 [8]. The modulation of IL-10 expression by different cells is complex, with common and cell-specific regulatory molecular mechanisms in place [6]. These mechanisms include epigenetic regulation, the expression and activation of particular transcription factors, the triggering of signalling pathways, and post-transcriptional regulation $[6,9]$. It is now evident that deregulation of these fine-tuned processes is associated with detrimental effects of IL-10. As such, understanding the regulation of IL-10 expression by different cells is instrumental for the targeted design of immune intervention strategies.

IL-10 production in the brain has also been described, but the cellular sources and regulatory molecular mechanisms involved are much less known than those operating at the periphery. Considering the potential of IL-10 in regulating the immune response in the brain, this lack of knowledge hampers the development of novel immune modulatory strategies. In this review, we start by providing a global view on the immune response in the central nervous system (CNS) and of the potential interest of IL-10 regulation in the context of neuroinflammation versus neurodegeneration and then discuss our current understanding on the molecular mechanisms underlying IL-10 production by CNS cells.

\section{Global concepts on the immune response in the CNS}

Although for decades the CNS has been considered an immune privileged site due to the believed absence of a local immune response, extensive work in the last decade unravelled the presence of a specialized intrinsic innate immune system in the CNS $[10,11]$. Indeed, we now know that immune surveillance actively occurs in the CNS and that its well-functioning is fundamental to maintain the CNS homeostasis [10, 11]. Furthermore, classical lymphatic vessels were recently discovered in the CNS dura mater $[12,13]$, establishing a direct interface to the peripheral immune system. Whereas the resident innate immune system patrols the CNS as a first line of defence, the presence of the adaptive immune response is controlled by a series of interfaces that include the brain-blood-barrier and the choroid plexus that likely represent a protective measure against immune-mediated damage [14].

The innate immune response is generally classified as the first line of defence against pathogens, being fast and relatively non-specific $[15,16]$. Innate immune cells express a wide variety of pattern recognition receptors (PRRs) which, upon recognition of danger signals, trigger a series of intracellular cascades that culminate with the production of immune mediators, among which pro- and anti-inflammatory cytokines [15]. Collectively, PRRs recognize pathogen-associated molecular patterns (PAMPs) present in pathogens and damage-associated molecular patterns (DAMPs) released by tissue damage in the absence of infection [16]. Whereas recognition of PAMPs initiates an immune response aimed at pathogen clearance, activation of PRRs via DAMPs aims at the resolution of tissue damage [15]. Recognition of PAMPs and DAMPs are critical for the organism homeostasis, and in both cases, the regulation of the initial immune response is needed, to avoid collateral tissue damage. Several cells of the CNS, including microglia, astrocytes, neurons, neural stem cells and endothelial cells express PRRs [11, 17-20], therefore contributing to the initiation of the innate immune response. The best-studied cellular population in this context is by far microglia.

Microglia are the resident macrophages of the brain and the only CNS cells of haematopoietic origin [21]. Microglia arise from the yolk sac-derived primitive macrophage population and migrate to the brain early in development, completing their maturation in the forming CNS [22, 23]. They are thus distinct from other glial cells (i.e. astrocytes and oligodendrocytes) and neurons, which are derived from the neuroectoderm [24], and a unique population among mononuclear phagocytes. Microglia are capable of self-renewal and do not appear to require replenishment from circulating bone marrow-originated monocytic precursors [25]. Nevertheless, in inflammatory conditions such as in experimental autoimmune encephalitis (EAE), circulating monocytes are recruited to the CNS, where they remain functionally distinct from microglia, and participate in disease progression [26, 27]. These infiltrating monocytes only contribute to the CNS myeloid cell pool in a transient manner [27]. In line with their myeloid origin, microglia express an array of PRRs and signalling molecules that allow their response to perturbations in brain homeostasis, namely with the production of several cytokines, chemokines and reactive oxygen and nitrogen species $[28,29]$. This response initially provides the environment needed for neuronal regeneration and functional recovery, thus being protective in its nature. However, a deregulated or non-resolving microglial inflammatory response may lead to the uncontrolled production of immune mediators and recruitment of peripheral immune cell populations, which induce secondary damage to intact tissue and inhibit post-injury CNS repair $[27,30]$. Indeed, deregulated microglial responses have been increasingly associated with a series of neurodegenerative disorders, from Alzheimer's and Parkinson's diseases to multiple sclerosis $[29,31,32]$. The classical view of microglia as the sole innate immune cells of the CNS has been challenged by findings that place astrocytes as immune players, with 
a critical role in the formation of the glial scar and tissue integrity restoration [33]. Similarly to microglial cells, astrocytes express PRRs, namely surface-expressed toll-like receptors (TLRs), which upon activation lead to the production of several inflammatory mediators [34, 35]. Finally, neurons, oligodendrocytes and endothelial cells also express PRRs [35-38] and therefore have the capacity to contribute to the inflammatory response in the brain.

\section{Neuroprotection vs neurodegeneration: a role for IL-10 in tipping this balance}

The manipulation of the balance between protective and degenerative neuroinflammation is gaining importance from a therapeutic point of view. Among the mechanisms in place to avoid exaggerated neuroimmune responses is the production of anti-inflammatory cytokines, such as IL-10. Binding of IL-10 to its receptor triggers a series of signalling cascades mediated by the Janus kinase (JAK) signal transducer and activator of transcription (STAT) pathway, particularly by STAT3 [39]. Signalling through the IL-10 receptor regulates several steps of the immune response, from decreasing cytokine gene expression to down-regulating the expression of major histocompatibility complex class II (MHC-II) and thus antigen presentation to T cells [39, 40]. Furthermore, IL-10 has been shown to prevent apoptosis by activating the phosphatidylinositol-4,5-bisphosphate-3-kinase (PI3K)/Akt cascade and enhancing the expression of anti-apoptotic factors as $\mathrm{Bcl}-2$ and $\mathrm{Bcl}-\mathrm{xl}$, whilst attenuating that of caspase- 3 [40]. The processes mediated by IL-10 (Fig. 1) have important implications at the CNS level. IL-10 is able to inhibit the production of pro-inflammatory cytokines by microglia, protecting astrocytes from excessive inflammation [41, 42]. IL10 also acts on astrocytes by potentiating their production of transforming growth factor (TGF)- $\beta$ [43]. In neurons, IL-10 receptor signalling has been associated with increased cellular survival $[44,45]$ and the regulation of adult neurogenesis $[46,47]$. Thus, IL-10 is an important mediator of the crosstalk between microglia, astrocytes and neurons. Importantly, in addition to the evidence placing $\mathrm{IL}-10$ as a regulator of the immune crosstalk in the CNS, several studies directly implicate defective IL-10 production or signalling in patients and animal models of neurological diseases, ranging from neuropathic pain [48] to multiple sclerosis $[49,50]$, Alzheimer's disease [51] or Parkinson's disease [52].

Microglia continuously survey the surrounding tissue environment, responding to any disturbance in neuronal homeostasis [53-55]. Depending on the detected insult and on the alterations to the microenvironmental niche, a spectrum of activated microglia results. The two extremes of this spectrum are M1 and M2 polarized cells, as described for macrophages of the periphery [56]. Upon detection of tissue injury or infection, or upon activation of microglial

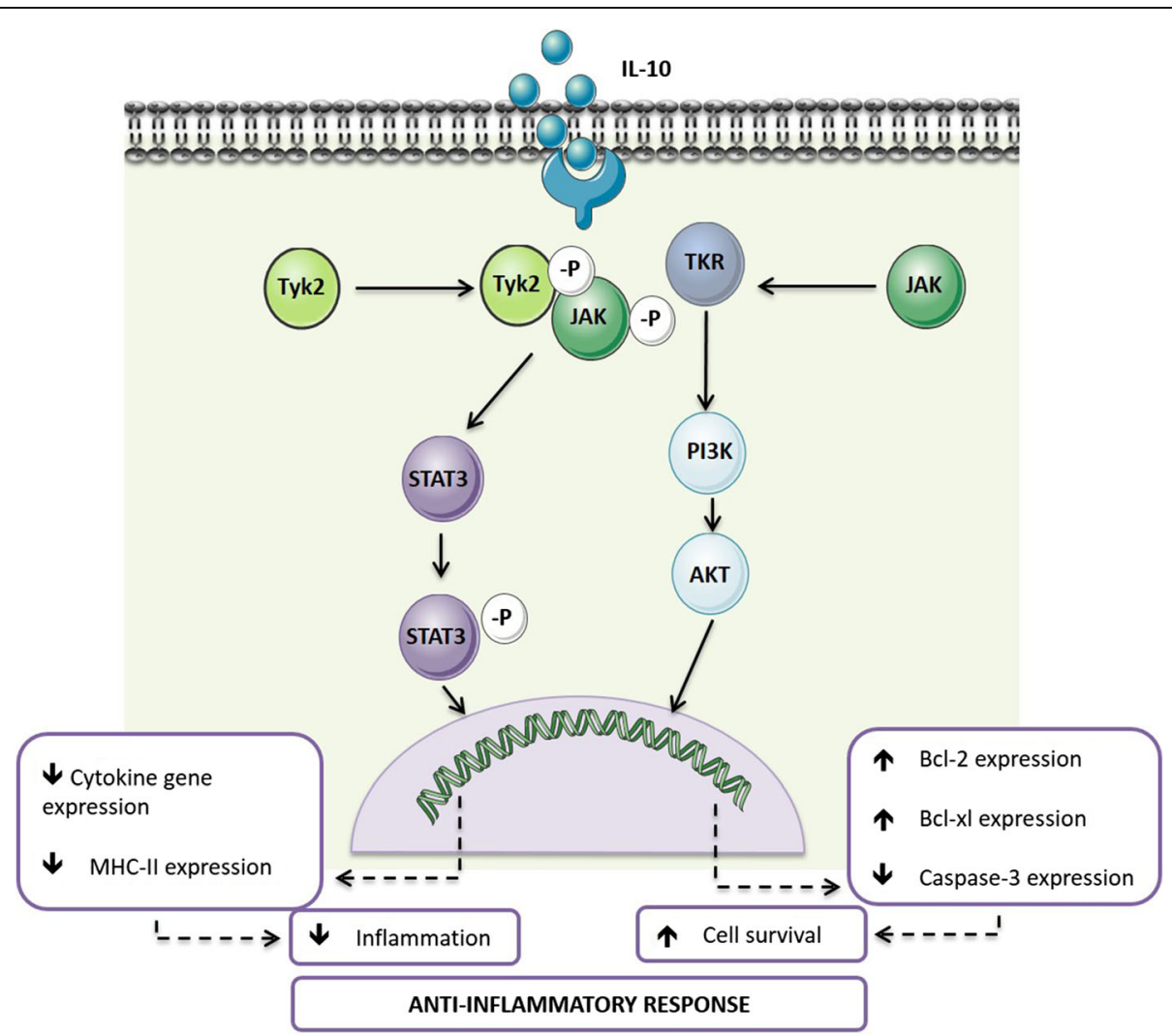

Fig. 1 The role of IL-10 receptor signalling in anti-inflammation. Overview of the IL-10R signalling cascade and the main cellular effects triggered by IL-10 
cultures with lipopolysaccharide (LPS) and interferon (IFN)$\gamma$, necrotic neurons, oligomers of amyloid- $\beta$ and $\alpha$-synuclein, microglia acquire an activated phenotype, typically referred to as classical or M1. This phenotype is characterized by the production of pro-inflammatory mediators, including cytokines, such as tumour necrosis factor (TNF), IL-6 and IL-1 $\beta$; chemokines; reactive oxygen species; nitric oxide; and prostaglandins [57]. Although important to fight infections or injury, most of the factors released by M1 microglia are toxic for neuronal cell cultures. At the other end of the spectrum, in the presence of IL-4, IL-13 or IL-10, microglia differentiate into M2 or alternative phenotype, characterized by the expression of IL-10; heparin-binding lectin (Ym1); cysteinerich protein FIZZ-1; and Arginase 1 [57]. The antiinflammatory M2 phenotype is neuroprotective and has been implicated in the resolution of the inflammation, phagocytosis and tissue repair. In recent years, the M1/M2 paradigm of microglial activation has been increasingly studied in several neurodegenerative and neurological diseases, where an imbalance towards M1 polarization is documented [58, 59]. Therefore, normalizing the imbalance between M1 and M2 microglial polarization states has been proposed as a therapeutic target for the treatment of several CNS-linked disorders $[60,61]$. In this context, in cell cultures, IL-10 in combination with IL-13 increased microglial secretion of activin-A, a neuroprotective TGF- $\beta$ superfamily member that promotes oligodendrocyte differentiation [62]. More recently, in vivo, IL-10 originated from regulatory $\mathrm{T}$ cells was shown to mediate microglia polarization towards the $\mathrm{M} 2$ phenotype ameliorating the outcome of intracerebral haemorrhage [63]. Other approaches to drive M2 microglia include the administration of anti-inflammatory agents [64], which action may well be mediated by IL-10, as they are known to enhance IL10 expression, as discussed below.

Taking all this together, a variety of methods to increase IL-10 and test its therapeutic potential in neurological disorders with an immune component have been developed. These include the administration of recombinant IL-10, the enhancement of IL-10 production through agonists, the delivery of IL-10 through viral vectors or the potentiation of IL-10-producing T and B regulatory cells [7, 65, 66]. However, despite the initially high expectations, the therapeutic success of IL-10 has been conflicting. Taking the case of multiple sclerosis as an example, the effect of IL-10 administration during EAE, varies from decreased, to no effect, to actual increased clinical scores [7, 67]. Several factors may explain the variability of outcomes upon IL-10-targeted interventions in EAE. Different studies use different routes of IL-10 administration, thus possibly compromising the bioavailability of IL-10 in the needed anatomical location. This is illustrated by the fact that intracranial administration of IL-10 improved the outcome of EAE [68], whereas systemic delivery did not [69]. Also, IL-10 appears to be generally more effective if delivered as gene therapy directly into the
CNS than as recombinant protein [7], which again may reflect the bioavailability of the molecule. Finally, data also suggest that IL-10 enhancement at disease onset, rather than later on, produced the best effects [66]. It is conceivable that with disease progression both IL-10-producing and IL-10-responding cells change, and so the action of IL10 also varies with time. In a recent study, nasal administration of a CD3-specific antibody was shown to ameliorate EAE in an IL-10-dependent manner [65], supporting the concept that IL-10 activating therapies may also be of interest. The observations reported in the context of EAE find parallel in other diseases where IL-10 appears as a possible therapeutic target, as recently reviewed by Kwilasz et al. [7]. To mention a few examples, a role for IL-10 in attenuating local inflammatory reactions during permanent ischemia has been described [70]. Also, adenoviral-mediated expression of human IL-10 in the striatum of mice subjected to MPTP (1-methyl-4-phenyl-1,2,3,6-tetrahydropyridine) neurotoxicant model of Parkinson's disease decreased the neurodegenerative effect of MPTP administration [71]. Importantly, the benefits of dampening neuroinflammation are highly dependent on the disease type. In the context of Alzheimer's disease, several studies show that skewing innate immunity towards a pro-inflammatory state reduce amyloid- $\beta$ deposition in transgenic mouse models, via enhancing amyloid- $\beta$ clearance by microglia [72-78]. In line with these findings, administration of IL-10 to the brains of amyloid precursor protein (APP) transgenic mice led to amyloid- $\beta$ accumulation accompanied by reduced amyloid$\beta$ phagocytosis by microglia [79]. The detrimental effects of IL-10 in Alzheimer's disease were further confirmed as IL10 absence in a transgenic mouse model of cerebral amyloidosis resulted in amyloid- $\beta$ phagocytosis by activated microglia and in reduced amyloid- $\beta$ load in the mouse brains, which ultimately conferred a better outcome of the disease [80]. Therefore, rebalancing the cerebral innate immunity by inhibiting actions of key anti-inflammatory cytokines, such as IL-10, to allow the brain return to a physiological state may also be a potential therapeutic strategy [80]. Thus, rewiring the immune response, at the functional, but also temporal and spatial levels, more than simply blocking inflammation, may prove a better approach to resolve the neuroimmune element of neurodegeneration. Therefore, a deep understanding of the cellular and molecular mechanisms operating to regulate the production of IL-10 is critical.

\section{Cellular sources of IL-10 in the CNS}

Microglial cells are the most investigated innate immune cells in the brain and thus the main studied cytokine producers, including of IL-10. Studies performed in vitro show that IL-10 production is induced in microglial cells upon TLR stimulation. Specifically, microglial cells produced IL10 upon TLR2, 3, 4 and 9 stimulation [34, 41, 81-84]. 
TLR-induced IL-10 production by microglia can be further regulated by other molecules. This is the case of adenosine that enhances the production of IL-10 by microglial cells upon stimulation of TLR2 and 4, whilst down-regulating the production of pro-inflammatory cytokines [85]. In vitro activation of purinergic receptors by extracellular ATP, either LPS-induced or exogenously provided, induced the production of IL-10 [86, 87]. Glutamate, the most common excitatory neurotransmitter, has also been shown to enhance the expression of IL-10 by LPS-stimulated microglial cells [81]. Prostaglandin $E_{2}$, an immune mediator present in inflammatory settings, is another example of molecules that enhance LPS-induced IL-10 expression and secretion [88]. Benfotiamine, a synthetic vitamin B1 derivate, downregulates the production of pro-inflammatory cytokines by TLR4-stimulated BV2 microglia cell line, whereas upregulating that of IL-10 [89]. Mycoepoxydiene was also shown to potentiate IL-10 production by TLR4-activated microglial cells, therefore reducing inflammatory markers [90]. Endocannabinoids enhance IL-10 production by activated microglia [91], as some anti-inflammatory drugs do [92]. Cytokines have also been described to impact IL-10 production by microglia. For example, tumour necrosis factor receptor 2 (TNFR2) triggering upon TLR4-induced TNF was shown to upregulate IL-10 production, which in this context was inhibited if in the presence of IFN- $\gamma$ [93]. This last observation has, however, been contradicted in another study showing that Th1 cell-derived IFN- $\gamma$ upregulates IL-10 production by microglial cells [94]. The production of IL-10 by microglia can also be induced in a PRRindependent manner. Glatiramer acetate, an immunomodulatory agent used in relapsing-remitting multiple sclerosis, was shown to induce secretion of IL-10 by microglial cells [95]. Resveratrol administration to a microglial cell line prevented hypoxia-induced injury by up-regulating IL-10 and controlling inflammation [96]. Collectively, these reports show that the molecules present in the microenvironment can impact IL-10 production by microglia, thus shaping the outcome of the inflammatory response. In addition to microglia, other CNS cells were shown to produce IL-10. Astrocytes produce IL-10 in response to PAMPs, as demonstrated in the case of the synthetic TLR3 ligand (double-stranded RNA) [97], Neisseria meningitidis or Borrelia burgdorferi [98], HIV membrane proteins [99] or human herpesvirus 6 if in the presence of IL-1 $\beta$, TNF or IFN- $\gamma$ [100]. Notably, stimulation of the Fcy receptor I on the surface of astrocytes also triggers an immune response, with production of IL-10 [101].

Identification of cellular sources of IL-10 in vivo is more difficult than in vitro, but many studies report the presence of IL-10 in the CNS. In vivo TLR4 stimulation upon peripheral or central injection of LPS into wild-type mice, leads to IL-10 production [52, 102, 103]. IL-10 was also shown to be elevated in the injured adult brain in several neurodegenerative diseases and animal models of disease, such as excitotoxic shock [104], multiple sclerosis [105, 106], EAE [107-109], middle cerebral artery occlusion [110], traumatic brain injury [111], Alzheimer's disease [112] and Parkinson's disease [113]. Although much is yet to know concerning IL-10 induction in the injured brain, in some situations it involved TLR signalling, supporting the importance of TLRs in inducing IL-10 in the brain. For example, IL-10 production during Alzheimer's disease occurs through a mechanism involving TLR4 [114]. In line with in vitro studies, anti-inflammatory drugs induce IL-10 production in vivo. In an experimental model of intracerebral haemorrhage, atorvastatin, a 3-hydroxy-3-methyl-glutarylcoenzyme A reductase inhibitor with known antiinflammatory properties, upregulated IL-10 in vivo, which is accompanied by a reduction in the number of activated microglial cells, and consequently to downregulate that of TNF [115].

Finally, it is important to refer that much of the immune mediators, including IL-10, present within the $\mathrm{CNS}$, in the context of disease, are produced by braininfiltrating immune cells. Initial activation of microglia results in the production of several pro-inflammatory mediators, which favour the brain-blood-barrier permeabilization and, ultimately, drive the infiltration of peripheral leukocytes into the CNS, including macrophages and T cells. Since macrophages, as microglia, detect PAMPs and DAMPs through the activation of PPRs, their arrival to the CNS will contribute to the full immune response established, either through the direct production of cytokines or indirectly through the modulation of the tissue microenvironment faced by microglia [116]. Likewise, infiltrating $\mathrm{T}$ cells may alter the cytokine milieu and thus reprogram microglia responses into M1 or M2 phenotypes [116]. Therefore, peripheral immune cells play a relevant role in the outcome of neuroinflammation associated with neurologic disorders.

\section{Molecular mechanisms regulating IL-10 production in the CNS}

Gene expression requires the accessibility of transcription factors to DNA, which is achieved through chromatin remodelling events [117]. DNA methylation, nucleosome remodelling and covalent histone modifications, such as acetylation or methylation, are among the factors that influence the accessibility of chromatin [118]. Although the epigenetics of the Il10 locus has been explored in macrophages, dendritic cells and $\mathrm{T}$ cells [6], to date it remains largely unknown in what concerns the regulation of IL-10 production by CNS cells. The level of methylation of the Il10 gene was shown to be an important regulator of Il10 mRNA transcription in microglial cells in the brains of rats subjected to morphine administration [119]. 
Several intracellular signalling cascades are known to regulate the production of IL-10 by microglia and astrocytes (Fig. 2). Among them are the mitogen-activated protein kinase (MAPKs) extracellular signal-regulated kinase (ERK) and p38, which signal downstream of PRR activation and act as positive regulators of IL-10 production in myeloid cells [6]. ERK activation is also associated with the induction of IL-10 production by microglial cells upon TLR4 triggering and in the presence of some IL-10 enhancers [90-92, 120]. ERK activation was also reported to enhance IL-10 production by astrocytes upon TLR3 stimulation [97]. Conflicting reports exist in what concerns the role of $\mathrm{p} 38$ activation in IL-10 production by microglia. Activation of $\mathrm{p} 38$ has been shown to induce IL10 expression in a microglial cell line upon adenosine administration [85]. However, in another study, a downregulation on the activation of p38 in LPS-stimulated rat primary cultured microglia has been correlated with an enhancement in IL-10 prodution [121]. This controversy may be due to the different models used in both works, and/or to the distinct stimuli provided to microglial cells that may activate different molecular pathways. Another pathway identified as an inducer of IL-10 production by macrophages and dendritic cells is the tyrosine kinase Syk [6]. The upregulation of IL-10 upon in vivo adrenalin injection and transient opening of the blood-brain-barrier, associated with the upregulation of the FcyRI, involved the downstream activation of Syk [122]. Finally, the signalling molecules protein kinase $\mathrm{R}$ (PKR), c-Jun $\mathrm{N}$-terminal kinase (JNK) and nuclear factor (NF) $-\kappa \beta$ have been identified as likely players in regulating the Il-10 expression in TLR3-activated astrocytes [97]. Activation of IL-10 expression in astrocytes and neurons through HIV membrane proteins was shown to involve the PI3K pathway, through the activation of the serine/threonine kinase p70 $[66,99]$. In all, several pathways have been involved in the regulation of IL-10 expression by microglia or astrocytes, illustrating the complexity of the system.

At the transcription factors level (Fig. 2), myocyte enhancer factor 2D (MEF2D) has been described to play an important role in activating IL-10 expression in microglia. MEF2D is present in microglial cells and increased upon microglia activation through TLR4, then binding to a MEF2 consensus site in the $I l 10$ promoter region, stimulating IL-10 transcription [123]. The transcription factor CREB was also shown to induce IL-10 expression downstream of p38 activation [85].

Post-transcriptional control of cytokine production is critical to ensure that the rapid transcription of cytokines in response to an initial stimulus is also rapidly turned off so that balanced amounts of pro- and antiinflammatory molecules are achieved [124]. This layer of regulation also operates to control the amount of IL-10 produced, being mostly studied in macrophages and

Enhancers of TLR-induced IL-10

- Mycoepoxydiene

- Anti-inflammatory compounds (eg KL-1037)

- Endocannabinoids (eg anandamide)

- Glutamate

- Prostaglandin E2

- Benfotiamine

- TNFR2 signaling

- ATP

Suppressors of TLR-induced IL-10

- IFN- $\gamma$

- IL-10

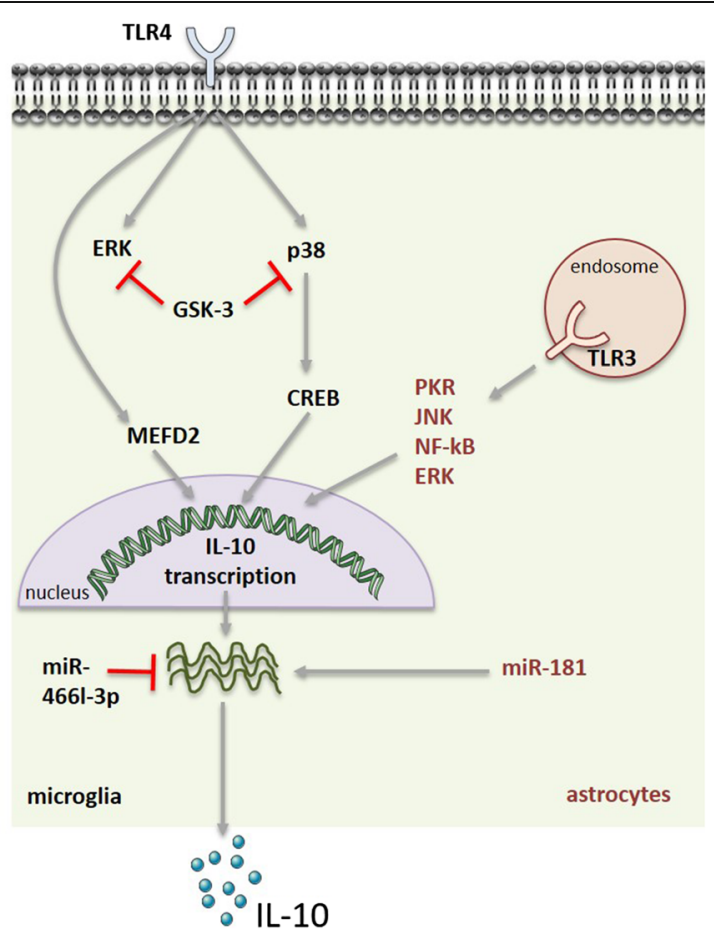

Fig. 2 Molecular mechanisms regulating IL-10 production in microglia and astrocytes. Signalling cascades, transcription factors and miRNAs involved in regulating the production of IL-10 in TLR-triggered microglia or astrocytes. Grey arrows indicate positive signals; red lines indicate IL-10 silencing pathways. Also indicated are known enhancers and blockers of IL-10 production 
dendritic cells, where both the IL-10 mRNA stability and the expression of specific microRNAs (miRs) are known to be regulated [9]. As for IL-10-producing CNS cells (Fig. 2), previous reports demonstrate that the production of IL-10 upon TLR4 stimulation is regulated by miRs. Indeed, the inhibition of miR-4661-3p upon LPS challenge of microglia is described to lead to an upregulation in the IL-10 production by these cells [125]. In astrocytes, the overexpression of another miR, miR-181, was found to enhance the amount of LPS-induced IL-10 production [126].

Importantly, several mechanisms operate as negative feedback loops to restrain IL-10 production by CNS cells (Fig. 2). Activation of the signalling cascade mediated by glycogen synthase kinase (GSK)-3 functions as an endogenous mechanism to inhibit IL-10 production, whilst enhancing the production of pro-inflammatory cytokines, by microglial cells upon TLR4 activation [127]. In line with this, abrogation of GSK-3, through chemical inhibitors or siRNA, was shown to restore TLR4-induced IL-10 production in microglia with a concomitant reduction in the levels of pro-inflammatory mediators [82, 128]. Furthermore, blockade of GSK-3 was shown to induce p38 and ERK, thus confirming the role for these MAPKs in enhancing IL-10 production [82]. A similar role for GSK-3 in regulating IL-10 was previously demonstrated for other immune cell types $[6,9]$. In both microglia and astrocytes, IL-10 was found to down-regulate its own transcription and that of the IL-10R when exogenously provided to untreated and LPS-treated cells [41].

\section{Conclusions}

The importance of the innate immune cells of the CNS to maintain the brain homeostasis is now fully accepted. In this context, the instrumental role of microglia for brain development and functionality is unquestionable [21]. Whether microglia activation is also instrumental for pathogen elimination, or whether mononuclear cells from the periphery do this job, remains unclear. In any case, the immune response triggered in the brain is critical to restore homeostasis upon injury. However, above a certain threshold, the initially immune-protective response may become immune-degenerative, by causing tissue damage. Given the demonstrated potential of IL-10 in modulating brain inflammatory settings, it is of major importance to understand how IL-10 production is regulated in innate immune cells of the CNS and how it impacts inflammatory responses in this compartment. Thus, unveiling the common and the cell-specific mechanisms regulating IL10 production in different settings and by different cellular populations will open new avenues for the development of specific targets to effectively and efficiently modulate IL10. For this, the development of more suitable animal models, for example cell-specific genetic manipulation of
IL-10, as well as deeper molecular studies of the processes underlying IL-10 expression and secretion, are required. Also of utmost importance is the understanding of the temporal and spatial dynamics of IL-10 production and action, so that the design of immune interventions may be optimized. This knowledge will potentiate the use of immunomodulatory, anti-inflammatory therapies targeting IL-10 production in several neurodegenerative conditions where inflammation is harmful.

\section{Abbreviations \\ APP: Amyloid precursor protein; CNS: Central nervous system; DAMP: Damage-associated molecular pattern; ERK: Extracellular signal-regulated kinase; GSK: Glycogen synthase kinase; IFN: Interferon; IL: Interleukin; JAK: Janus kinase; JNK: c-Jun N-terminal kinase; LPS: Lipopolysaccharide; MAPK: Mitogen-activated protein kinase; MEF2D: Myocyte enhancer factor 2D; MHC-II: Major histocompatibility complex class II; miR: MicroRNAs; NF: Nuclear factor; PAMP: Pathogen-associated molecular pattern; PI3K: Phosphatidylinositol-4,5- bisphosphate-3-kinase; PKR: Protein kinase R; PRR: Pattern recognition receptor; STAT: Signal transducer and activator of transcription; TGF: Transforming growth factor; Th: Thelper; TLR: Toll-like receptor; TNF: Tumour necrosis factor}

\section{Acknowledgements}

Not applicable.

\section{Funding}

We acknowledge the Portuguese Foundation for Science and Technology (FCT) for providing a PhD grant to DLS (SFRH/BD/88081/2012) and a post-doctoral fellowship to SR (SFRH/BPD/72710/2010). DS, AGC and SR were funded by FEDER through the Competitiveness Factors Operational Programme (COMPETE) and National Funds through FCT under the scope of the project POCI-01-0145-FEDER007038; and by the project NORTE-01-0145-FEDER-000013, supported by Norte Portugal Regional Operational Programme (NORTE 2020), under the PORTUGAL 2020 Partnership Agreement, through the European Regional Development Fund (ERDF). The MS lab was financed by Fundo Europeu de Desenvolvimento Regional (FEDER) funds through the COMPETE 2020-Operacional Programme for Competitiveness and Internationalisation (POCI), Portugal 2020, and by Portuguese funds through FCT in the framework of the project "Institute for Research and Innovation in Health Sciences" (POCI-01-0145-FEDER-007274). MS is a FCT Associate Investigator. The funding body had no role in the design of the study and collection, analysis, and interpretation of the data and in writing the manuscript.

\section{Availability of data and materials}

Data sharing is not applicable to this article as no datasets were generated or analysed during the current study.

Authors' contributions

DS, GMC, AGC, SR and MS wrote the manuscript. All authors read and approved the final manuscript.

\section{Competing interests}

The authors declare that they have no competing interests.

\section{Consent for publication}

Not applicable.

\section{Ethics approval and consent to participate}

Not applicable.

\section{Author details}

${ }^{1}$ Life and Health Sciences Research Institute (ICVS), School of Health Sciences, University of Minho, Braga, Portugal. ${ }^{2}$ ICVS/3B's PT Government Associate Laboratory, Braga, Portugal. ${ }^{3} \mathrm{i} 3 \mathrm{~S}$ - Instituto de Investigação e Inovação em Saúde, Universidade do Porto, Rua Alfredo Allen, 208, 4200-135 Porto, Portugal. ${ }^{4} \mathrm{IBMC}$ - Instituto de Biologia Molecular e Celular, Universidade do Porto, Porto, Portugal.

Received: 21 September 2016 Accepted: 11 November 2016 Published online: 24 November 2016 


\section{References}

1. Fiorentino DF, Bond MW, Mosmann TR. Two types of mouse T helper cell. IV. Th2 clones secrete a factor that inhibits cytokine production by Th1 clones. J Exp Med. 1989;170:2081-95.

2. O'Garra A, Vieira P. T(H)1 cells control themselves by producing interleukin-10. Nat Rev Immunol. 2007:7:425-8.

3. Kuhn R, Lohler J, Rennick D, Rajewsky K, Muller W. Interleukin-10-deficient mice develop chronic enterocolitis. Cell. 1993;75:263-74.

4. Engelhardt KR, Grimbacher B. IL-10 in humans: lessons from the gut, IL-10/ IL-10 receptor deficiencies, and IL-10 polymorphisms. Curr Top Microbiol Immunol. 2014:380:1-18.

5. Dennis KL, Blatner NR, Gounari F, Khazaie K. Current status of interleukin-10 and regulatory T-cells in cancer. Curr Opin Oncol. 2013;25:637-45.

6. Saraiva M, O'Garra A. The regulation of IL-10 production by immune cells. Nat Rev Immunol. 2010;10:170-81.

7. Kwilasz AJ, Grace PM, Serbedzija P, Maier SF, Watkins LR. The therapeutic potential of interleukin-10 in neuroimmune diseases. Neuropharmacology. 2015;96:55-69.

8. Jarry A, Bossard C, Bou-Hanna C, Masson D, Espaze E, Denis MG, Laboisse CL. Mucosal IL-10 and TGF-beta play crucial roles in preventing LPS-driven, IFN-gamma-mediated epithelial damage in human colon explants. J Clin Invest. 2008;118:1132-42

9. Gabrysova L, Howes A, Saraiva M, O'Garra A. The regulation of IL-10 expression. Curr Top Microbiol Immunol. 2014;380:157-90.

10. Rivest $\mathrm{S}$. Regulation of innate immune responses in the brain. Nat Rev Immunol. 2009:9:429-39.

11. Lampron A, Elali A, Rivest S. Innate immunity in the CNS: redefining the relationship between the CNS and Its environment. Neuron. 2013:78:214-32.

12. Louveau A, Smirnov I, Keyes TJ, Eccles JD, Rouhani SJ, Peske JD, Derecki NC, Castle D, Mandell JW, Lee KS, et al. Structural and functional features of central nervous system lymphatic vessels. Nature. 2015;523:337-41.

13. Aspelund A, Antila S, Proulx ST, Karlsen TV, Karaman S, Detmar M, Wiig H, Alitalo K. A dural lymphatic vascular system that drains brain interstitial fluid and macromolecules. J Exp Med. 2015;212:991-9.

14. Banks WA, Erickson MA. The blood-brain barrier and immune function and dysfunction. Neurobiol Dis. 2010;37:26-32.

15. Iwasaki A, Medzhitov R. Control of adaptive immunity by the innate immune system. Nat Immunol. 2015;16:343-53.

16. Takeuchi O, Akira S. Pattern recognition receptors and inflammation. Cell. 2010:140:805-20.

17. Rolls A, Shechter R, London A, Ziv Y, Ronen A, Levy R, Schwartz M. Toll-like receptors modulate adult hippocampal neurogenesis. Nat Cell Biol. 2007:9:1081-8.

18. Okun E, Griffioen KJ, Son TG, Lee JH, Roberts NJ, Mughal MR, Hutchison E, Cheng A, Arumugam TV, Lathia JD, et al. TLR2 activation inhibits embryonic neural progenitor cell proliferation. J Neurochem. 2010;114:462-74.

19. Okun E, Griffioen K, Barak B, Roberts NJ, Castro K, Pita MA, Cheng A, Mughal MR, Wan R, Ashery U, Mattson MP. Toll-like receptor 3 inhibits memory retention and constrains adult hippocampal neurogenesis. Proc Natl Acad Sci U S A. 2010;107:15625-30.

20. Hanamsagar R, Hanke ML, Kielian T. Toll-like receptor (TLR) and inflammasome actions in the central nervous system. Trends Immunol. 2012;33:333-42.

21. Crotti A, Ransohoff RM. Microglial physiology and pathophysiology: insights from genome-wide transcriptional profiling. Immunity. 2016;44:505-15.

22. Ginhoux F, Greter M, Leboeuf M, Nandi S, See P, Gokhan S, Mehler MF, Conway SJ, Ng LG, Stanley ER, et al. Fate mapping analysis reveals that adult microglia derive from primitive macrophages. Science. 2010;330:841-5.

23. Kierdorf K, Erny D, Goldmann T, Sander V, Schulz C, Perdiguero EG, Wieghofer P, Heinrich A, Riemke P, Holscher C, et al. Microglia emerge from erythromyeloid precursors via Pu.1- and Irf8-dependent pathways. Nat Neurosci. 2013;16:273-80.

24. Guerout N, Li X, Barnabe-Heider F. Cell fate control in the developing central nervous system. Exp Cell Res. 2014;321:77-83.

25. Ajami B, Bennett JL, Krieger C, Tetzlaff W, Rossi FM. Local self-renewal can sustain CNS microglia maintenance and function throughout adult life. Nat Neurosci. 2007:10:1538-43.

26. Yamasaki R, Lu H, Butovsky O, Ohno N, Rietsch AM, Cialic R, Wu PM, Doykan CE, Lin J, Cotleur AC, et al. Differential roles of microglia and monocytes in the inflamed central nervous system. J Exp Med. 2014;211:1533-49.

27. Amor S, Woodroofe MN. Innate and adaptive immune responses in neurodegeneration and repair. Immunology. 2014;141:287-91.
28. Saijo K, Glass CK. Microglial cell origin and phenotypes in health and disease. Nat Rev Immunol. 2011:11:775-87.

29. Su F, Bai F, Zhou H, Zhang Z. Microglial toll-like receptors and Alzheimer's disease. Brain Behav Immun. 2016:52:187-98.

30. Amor S, Peferoen LA, Vogel DY, Breur M, van der Valk P, Baker D, van Noort JM. Inflammation in neurodegenerative diseases - an update. Immunology. 2014;142:151-66.

31. Sanchez-Guajardo $V$, Tentillier N, Romero-Ramos M. The relation between alpha-synuclein and microglia in Parkinson's disease: recent developments. Neuroscience. 2015;302:47-58.

32. Mandolesi G, Grasselli G, Musumeci G, Centonze D. Cognitive deficits in experimental autoimmune encephalomyelitis: neuroinflammation and synaptic degeneration. Neurol Sci. 2010;31:S255-9.

33. Farina C, Aloisi F, Meinl E. Astrocytes are active players in cerebral innate immunity. Trends Immunol. 2007:28:138-45.

34. Jack CS, Arbour N, Manusow J, Montgrain V, Blain M, McCrea E, Shapiro A, Antel JP. TLR signaling tailors innate immune responses in human microglia and astrocytes. J Immunol. 2005;175:4320-30.

35. Bsibsi M, Ravid R, Gveric D, van Noort JM. Broad expression of Toll-like receptors in the human central nervous system. J Neuropathol Exp Neurol. 2002;61:1013-21.

36. Tang SC, Arumugam TV, Xu X, Cheng A, Mughal MR, Jo DG, Lathia JD, Siler DA, Chigurupati S, Ouyang $X$, et al. Pivotal role for neuronal Toll-like receptors in ischemic brain injury and functional deficits. Proc Natl Acad Sci U S A. 2007;104:13798-803.

37. Lafon $M$, Megret $F$, Lafage M, Prehaud C. The innate immune facet of brain: human neurons express TLR-3 and sense viral dsRNA. J Mol Neurosci. 2006; 29:185-94.

38. Mai J, Virtue A, Shen J, Wang H, Yang XF. An evolving new paradigm: endothelial cells_conditional innate immune cells. J Hematol Oncol. 2013:6:61.

39. Murray PJ. Understanding and exploiting the endogenous interleukin-10/STAT3mediated anti-inflammatory response. Curr Opin Pharmacol. 2006:6:379-86.

40. Moore KW, de Waal MR, Coffman RL, O'Garra A. Interleukin-10 and the interleukin-10 receptor. Annu Rev Immunol. 2001;19:683-765.

41. Ledeboer A, Breve JJ, Wierinckx A, van der Jagt S, Bristow AF, Leysen JE, Tilders FJ, Van Dam AM. Expression and regulation of interleukin-10 and interleukin-10 receptor in rat astroglial and microglial cells. Eur J Neurosci. 2002;16:1175-85.

42. Balasingam V, Yong WW. Attenuation of astroglial reactivity by interleukin-10. Neurosci. 1996:16:2945-55.

43. Norden DM, Fenn AM, Dugan A, Godbout JP. TGFbeta produced by IL-10 redirected astrocytes attenuates microglial activation. Glia. 2014;62:881-95.

44. Zhou Z, Peng X, Insolera R, Fink DJ, Mata M. Interleukin-10 provides direct trophic support to neurons. J Neurochem. 2009;110:1617-27.

45. Zhou Z, Peng X, Insolera R, Fink DJ, Mata M. IL-10 promotes neuronal survival following spinal cord injury. Exp Neurol. 2009;220:183-90.

46. Pereira L, Font-Nieves M, Van den Haute C, Baekelandt V, Planas AM, Pozas E. IL-10 regulates adult neurogenesis by modulating ERK and STAT3 activity. Front Cell Neurosci. 2015:9:57.

47. Perez-Asensio FJ, Perpina U, Planas AM, Pozas E. Interleukin-10 regulates progenitor differentiation and modulates neurogenesis in adult brain. J Cell Sci. 2013;126:4208-19.

48. George A, Kleinschnitz C, Zelenka M, Brinkhoff J, Stoll G, Sommer C. Wallerian degeneration after crush or chronic constriction injury of rodent sciatic nerve is associated with a depletion of endoneurial interleukin-10 protein. Exp Neurol. 2004;188:187-91.

49. Hesse D, Krakauer M, Lund H, Sondergaard HB, Limborg SJ, Sorensen PS, Sellebjerg F. Disease protection and interleukin-10 induction by endogenous interferon-beta in multiple sclerosis? Eur J Neurol. 2011;18:266-72.

50. van Boxel-Dezaire AH, Hoff SC, van Oosten BW, Verweij CL, Drager AM, Ader $\mathrm{HJ}$, van Houwelingen JC, Barkhof F, Polman CH, Nagelkerken L. Decreased interleukin-10 and increased interleukin-12p40 mRNA are associated with disease activity and characterize different disease stages in multiple sclerosis. Ann Neurol. 1999:45:695-703.

51. Kiyota T, Ingraham KL, Swan RJ, Jacobsen MT, Andrews SJ, Ikezu T. AAV serotype 2/1-mediated gene delivery of anti-inflammatory interleukin-10 enhances neurogenesis and cognitive function in APP+PS1 mice. Gene Ther. 2012:19:724-33.

52. Arimoto T, Choi DY, Lu X, Liu M, Nguyen XV, Zheng N, Stewart CA, Kim HC, Bing $\mathrm{G}$. Interleukin-10 protects against inflammation-mediated degeneration of dopaminergic neurons in substantia nigra. Neurobiol Aging. 2007;28:894-906. 
53. Wu Y, Dissing-Olesen L, MacVicar BA, Stevens B. Microglia: dynamic mediators of synapse development and plasticity. Trends Immunol. 2015;36:605-13.

54. Sipe GO, Lowery RL, Tremblay ME, Kelly EA, Lamantia CE, Majewska AK. Microglial P2Y12 is necessary for synaptic plasticity in mouse visual cortex. Nat Commun. 2016;7:10905.

55. Paolicelli RC, Bolasco G, Pagani F, Maggi L, Scianni M, Panzanelli P, Giustetto $M$, Ferreira TA, Guiducci E, Dumas $L$, et al. Synaptic pruning by microglia is necessary for normal brain development. Science. 2011;333:1456-8.

56. Martinez FO, Helming L, Gordon S. Alternative activation of macrophages: an immunologic functional perspective. Annu Rev Immunol. 2009;27:451-83.

57. Fernandes A, Miller-Fleming L, Pais TF. Microglia and inflammation: conspiracy, controversy or control? Cell Mol Life Sci. 2014;71:3969-85.

58. Nakagawa Y, Chiba K. Diversity and plasticity of microglial cells in psychiatric and neurological disorders. Pharmacol Ther. 2015;154:21-35.

59. Tang $Y$, Le W. Differential roles of $M 1$ and M2 microglia in neurodegenerative diseases. Mol Neurobiol. 2016;53:1181-94.

60. Chio CC, Lin MT, Chang CP. Microglial activation as a compelling target for treating acute traumatic brain injury. Curr Med Chem. 2015;22:759-70.

61. Amantea D, Micieli G, Tassorelli C, Cuartero MI, Ballesteros I, Certo M, Moro MA, Lizasoain I, Bagetta G. Rational modulation of the innate immune system for neuroprotection in ischemic stroke. Front Neurosci. 2015;9:147.

62. Miron VE, Boyd A, Zhao JW, Yuen TJ, Ruckh JM, Shadrach JL, van Wijngaarden P, Wagers AJ, Williams A, Franklin RJ, ffrench-Constant C. M2 microglia and macrophages drive oligodendrocyte differentiation during CNS remyelination. Nat Neurosci. 2013;16:1211-8.

63. Zhou K, Zhong Q, Wang YC, Xiong XY, Meng ZY, Zhao T, Zhu WY, Liao MF, Wu LR, Yang YR, et al. Regulatory T cells ameliorate intracerebral hemorrhage-induced inflammatory injury by modulating microglia/ macrophage polarization through the IL-10/GSK3beta/PTEN axis. J Cereb Blood Flow Metab. 2016.

64. Franco R, Fernandez-Suarez D. Alternatively activated microglia and macrophages in the central nervous system. Prog Neurobiol. 2015;131:65-86.

65. Mayo L, Cunha AP, Madi A, Beynon V, Yang Z, Alvarez Jl, Prat A, Sobel RA, Kobzik L, Lassmann H, et al. IL-10-dependent Tr1 cells attenuate astrocyte activation and ameliorate chronic central nervous system inflammation. Brain. 2016;139:1939-57.

66. Han J, Sun L, Fan X, Wang Z, Cheng Y, Zhu J, Jin T. Role of regulatory b cells in neuroimmunologic disorders. J Neurosci Res. 2016;94:693-701.

67. Saxena A, Khosraviani S, Noel S, Mohan D, Donner T, Hamad AR. Interleukin10 paradox: a potent immunoregulatory cytokine that has been difficult to harness for immunotherapy. Cytokine. 2015;74:27-34

68. Cua DJ, Hutchins B, LaFace DM, StohIman SA, Coffman RL. Central nervous system expression of IL-10 inhibits autoimmune encephalomyelitis. J Immunol. 2001;166:602-8.

69. Croxford JL, Feldmann M, Chernajovsky Y, Baker D. Different therapeutic outcomes in experimental allergic encephalomyelitis dependent upon the mode of delivery of IL-10: a comparison of the effects of protein, adenoviral or retroviral IL-10 delivery into the central nervous system. J Immunol. 2001;166:4124-30.

70. Perez-de Puig I, Miro F, Salas-Perdomo A, Bonfill-Teixidor E, Ferrer-Ferrer M, Marquez-Kisinousky L, Planas AM. IL-10 deficiency exacerbates the brain inflammatory response to permanent ischemia without preventing resolution of the lesion. J Cereb Blood Flow Metab. 2013;33:1955-66.

71. Joniec-Maciejak I, Ciesielska A, Wawer A, Sznejder-Pacholek A, Schwenkgrub J, Cudna A, Hadaczek P, Bankiewicz KS, Czlonkowska A, Czlonkowski A. The influence of AAV2-mediated gene transfer of human IL-10 on neurodegeneration and immune response in a murine model of Parkinson's disease. Pharmacol Rep. 2014;66:660-9.

72. Boissonneault V, Filali M, Lessard M, Relton J, Wong G, Rivest S. Powerful beneficial effects of macrophage colony-stimulating factor on beta-amyloid deposition and cognitive impairment in Alzheimer's disease. Brain. 2009;132:1078-92.

73. Chakrabarty P, Ceballos-Diaz C, Beccard A, Janus C, Dickson D, Golde TE, Das P. IFN-gamma promotes complement expression and attenuates amyloid plaque deposition in amyloid beta precursor protein transgenic mice. J Immunol. 2010;184:5333-43.

74. Chakrabarty P, Herring A, Ceballos-Diaz C, Das P, Golde TE. Hippocampal expression of murine TNFalpha results in attenuation of amyloid deposition in vivo. Mol Neurodegener. 2011;6:16.

75. El Khoury J, Toft M, Hickman SE, Means TK, Terada K, Geula C, Luster AD. Ccr2 deficiency impairs microglial accumulation and accelerates progression of Alzheimer-like disease. Nat Med. 2007;13:432-8.

76. Herber DL, Mercer M, Roth LM, Symmonds K, Maloney J, Wilson N, Freeman MJ, Morgan D, Gordon MN. Microglial activation is required for Abeta clearance after intracranial injection of lipopolysaccharide in APP transgenic mice. J Neuroimmune Pharmacol. 2007;2:222-31.

77. Naert G, Rivest S. CC chemokine receptor 2 deficiency aggravates cognitive impairments and amyloid pathology in a transgenic mouse model of Alzheimer's disease. J Neurosci. 2011;31:6208-20.

78. Shaftel SS, Kyrkanides S, Olschowka JA, Miller JN, Johnson RE, O'Banion MK. Sustained hippocampal IL-1 beta overexpression mediates chronic neuroinflammation and ameliorates Alzheimer plaque pathology. J Clin Invest. 2007;117:1595-604.

79. Chakrabarty P, Li A, Ceballos-Diaz C, Eddy JA, Funk CC, Moore B, DiNunno N Rosario AM, Cruz PE, Verbeeck C, et al. IL-10 alters immunoproteostasis in APP mice, increasing plaque burden and worsening cognitive behavior. Neuron. 2015;85:519-33.

80. Guillot-Sestier MV, Doty KR, Gate D, Rodriguez Jr J, Leung BP, Rezai-Zadeh K, Town T. II10 deficiency rebalances innate immunity to mitigate Alzheimerlike pathology. Neuron. 2015;85:534-48.

81. Werry EL, Liu GJ, Lovelace MD, Nagarajah R, Hickie IB, Bennett MR. Lipopolysaccharide-stimulated interleukin-10 release from neonatal spinal cord microglia is potentiated by glutamate. Neuroscience. 2011;175:93-103.

82. Huang WC, Lin YS, Wang CY, Tsai CC, Tseng HC, Chen CL, Lu PJ, Chen PS, Qian L, Hong JS, Lin CF. Glycogen synthase kinase-3 negatively regulates anti-inflammatory interleukin-10 for lipopolysaccharide-induced iNOS/NO biosynthesis and RANTES production in microglial cells. Immunology. 2009; 128:e275-86

83. Olson JK, Miller SD. Microglia initiate central nervous system innate and adaptive immune responses through multiple TLRs. J Immunol. 2004; 173:3916-24.

84. Mizuno T, Sawada M, Marunouchi T, Suzumura A. Production of interleukin10 by mouse glial cells in culture. Biochem Biophys Res Commun. 1994;205: 1907-15.

85. Koscso B, Csoka B, Selmeczy Z, Himer L, Pacher P, Virag L, Hasko G. Adenosine augments IL-10 production by microglial cells through an A2B adenosine receptor-mediated process. J Immunol. 2012;188:445-53.

86. Seo DR, Kim KY, Lee YB. Interleukin-10 expression in lipopolysaccharideactivated microglia is mediated by extracellular ATP in an autocrine fashion. Neuroreport. 2004;15:1157-61.

87. Seo DR, Kim SY, Kim KY, Lee HG, Moon JH, Lee JS, Lee SH, Kim SU, Lee YB. Cross talk between P2 purinergic receptors modulates extracellular ATPmediated interleukin-10 production in rat microglial cells. Exp Mol Med. 2008:40:19-26.

88. Aloisi F, De Simone R, Columba-Cabezas S, Levi G. Opposite effects of interferon-gamma and prostaglandin E2 on tumor necrosis factor and interleukin-10 production in microglia: a regulatory loop controlling microglia pro- and anti-inflammatory activities. J Neurosci Res. 1999;56:571-80.

89. Bozic I, Savic D, Laketa D, Bjelobaba I, Milenkovic I, Pekovic S, Nedeljkovic N, Lavrnja I. Benfotiamine attenuates inflammatory response in LPS stimulated BV-2 microglia. PLoS One. 2015;10:e0118372.

90. Su X, Chen Q, Chen W, Chen T, Li W, Li Y, Dou X, Zhang Y, Shen Y, Wu H, Yu C. Mycoepoxydiene inhibits activation of BV2 microglia stimulated by lipopolysaccharide through suppressing NF-kappaB, ERK 1/2 and toll-like receptor pathways. Int Immunopharmacol. 2014;19:88-93.

91. Correa F, Hernangomez M, Mestre L, Loria F, Spagnolo A, Docagne F, Di Marzo V, Guaza C. Anandamide enhances IL-10 production in activated microglia by targeting $\mathrm{CB}(2)$ receptors: roles of ERK1/2, JNK, and NF-kappaB. Glia. 2010;58:135-47.

92. Kim WK, Jang PG, Woo MS, Han IO, Piao HZ, Lee K, Lee H, Joh TH, Kim HS. A new anti-inflammatory agent KL-1037 represses proinflammatory cytokine and inducible nitric oxide synthase (iNOS) gene expression in activated microglia. Neuropharmacology. 2004;47:243-52.

93. Veroni C, Gabriele L, Canini I, Castiello L, Coccia E, Remoli ME, ColumbaCabezas S, Arico E, Aloisi F, Agresti C. Activation of TNF receptor 2 in microglia promotes induction of anti-inflammatory pathways. Mol Cel Neurosci. 2010;45:234-44.

94. Ishii H, Tanabe S, Ueno M, Kubo T, Kayama H, Serada S, Fujimoto M, Takeda K, Naka T, Yamashita T. ifn-gamma-dependent secretion of IL-10 from Th1 cells and microglia/macrophages contributes to functional recovery after spinal cord injury. Cell Death Dis. 2013;4:e710.

95. Pul R, Moharregh-Khiabani D, Skuljec J, Skripuletz T, Garde N, Voss EV, Stangel M. Glatiramer acetate modulates TNF-alpha and IL-10 secretion in microglia and promotes their phagocytic activity. J Neuroimmune Pharmacol. 2011;6:381-8. 
96. Song J, Cheon SY, Jung W, Lee WT, Lee JE. Resveratrol induces the expression of interleukin-10 and brain-derived neurotrophic factor in BV2 microglia under hypoxia. Int J Mol Sci. 2014;15:15512-29.

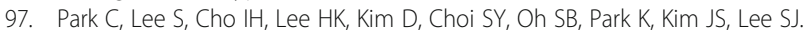
TLR3-mediated signal induces proinflammatory cytokine and chemokine gene expression in astrocytes: differential signaling mechanisms of TLR3induced IP-10 and IL-8 gene expression. Glia. 2006;53:248-56.

98. Rasley A, Tranguch SL, Rati DM, Marriott I. Murine glia express the immunosuppressive cytokine, interleukin-10, following exposure to Borrelia burgdorferi or Neisseria meningitidis. Glia. 2006;53:583-92.

99. Speth C, Joebstl B, Barcova M, Dierich MP. HIV-1 envelope protein gp41 modulates expression of interleukin-10 and chemokine receptors on monocytes, astrocytes and neurones. AIDS. 2000;14:629-36.

100. Meeuwsen S, Persoon-Deen C, Bsibsi M, Bajramovic JJ, Ravid R, De Bolle L, van Noort JM. Modulation of the cytokine network in human adult astrocytes by human herpesvirus-6A. J Neuroimmunol. 2005;164:37-47.

101. Blanco AM, Valles SL, Pascual M, Guerri C. Involvement of TLR4/type I IL-1 receptor signaling in the induction of inflammatory mediators and cell death induced by ethanol in cultured astrocytes. J Immunol. 2005;175:6893-9.

102. Henry CJ, Huang Y, Wynne AM, Godbout JP. Peripheral lipopolysaccharide (LPS) challenge promotes microglial hyperactivity in aged mice that is associated with exaggerated induction of both pro-inflammatory IL-1beta and anti-inflammatory IL-10 cytokines. Brain Behav Immun. 2009;23:309-17.

103. Fenn AM, Henry CJ, Huang Y, Dugan A, Godbout JP. Lipopolysaccharideinduced interleukin (IL)-4 receptor-alpha expression and corresponding sensitivity to the M2 promoting effects of IL-4 are impaired in microglia of aged mice. Brain Behav Immun. 2012;26:766-77.

104. Gonzalez P, Burgaya F, Acarin L, Peluffo H, Castellano B, Gonzalez B. Interleukin-10 and interleukin-10 receptor-I are upregulated in glial cells after an excitotoxic injury to the postnatal rat brain. J Neuropathol Exp Neurol. 2009;68:391-403.

105. Dendrou CA, Fugger L, Friese MA. Immunopathology of multiple sclerosis. Nat Rev Immunol. 2015;15:545-58.

106. Hulshof S, Montagne L, De Groot CJ, Van Der Valk P. Cellular localization and expression patterns of interleukin-10, interleukin-4, and their receptors in multiple sclerosis lesions. Glia. 2002;38:24-35.

107. Ledeboer A, Wierinckx A, Bol JG, Floris S, Renardel de Lavalette C, De Vries HE, van den Berg TK, Dijkstra CD, Tilders FJ, Van Dam AM. Regional and temporal expression patterns of interleukin-10, interleukin-10 receptor and adhesion molecules in the rat spinal cord during chronic relapsing EAE. J Neuroimmunol. 2003;136:94-103.

108. Jander S, Pohl J, D'Urso D, Gillen C, Stoll G. Time course and cellular localization of interleukin-10 mRNA and protein expression in autoimmune inflammation of the rat central nervous system. Am J Pathol. 1998;152:975-82.

109. Blazevski J, Petkovic F, Momcilovic M, Jevtic B, Miljkovic D, Mostarica SM. High interleukin-10 expression within the central nervous system may be important for initiation of recovery of Dark Agouti rats from experimental autoimmune encephalomyelitis. Immunobiology. 2013;218:1192-9.

110. Zhai QH, Futrell N, Chen FJ. Gene expression of IL-10 in relationship to TNFalpha, IL-1beta and IL-2 in the rat brain following middle cerebral artery occlusion. J Neurol Sci. 1997;152:119-24.

111. Kamm K, Vanderkolk W, Lawrence C, Jonker M, Davis AT. The effect of traumatic brain injury upon the concentration and expression of interleukin1 beta and interleukin-10 in the rat. J Trauma. 2006;60:152-7.

112. Apelt J, Schliebs R. Beta-amyloid-induced glial expression of both pro- and anti-inflammatory cytokines in cerebral cortex of aged transgenic Tg2576 mice with Alzheimer plaque pathology. Brain Res. 2001;894:21-30.

113. Rentzos M, Nikolaou C, Andreadou E, Paraskevas GP, Rombos A, Zoga M, Tsoutsou A, Boufidou F, Kapaki E, Vassilopoulos D. Circulating interleukin-10 and interleukin-12 in Parkinson's disease. Acta Neurol Scand. 2009;119:332-7.

114. Jin JJ, Kim HD, Maxwell JA, Li L, Fukuchi K. Toll-like receptor 4-dependent upregulation of cytokines in a transgenic mouse model of Alzheimer's disease. J Neuroinflammation. 2008:5:23.

115. Ewen T, Qiuting L, Chaogang T, Tao T, Jun W, Liming T, Guanghong X. Neuroprotective effect of atorvastatin involves suppression of TNF-alpha and upregulation of IL-10 in a rat model of intracerebral hemorrhage. Cell Biochem Biophys. 2013;66:337-46.

116. Gonzalez H, Elgueta D, Montoya A, Pacheco R. Neuroimmune regulation of microglial activity involved in neuroinflammation and neurodegenerative diseases. J Neuroimmunol. 2014;274:1-13.
117. Garcia-Gonzalez E, Escamilla-Del-Arenal M, Arzate-Mejia R, Recillas-Targa F. Chromatin remodeling effects on enhancer activity. Cell Mol Life Sci. 2016; 73(15):2897-910.

118. Jenuwein T, Allis CD. Translating the histone code. Science. 2001;293:1074-80.

119. Schwarz JM, Hutchinson MR, Bilbo SD. Early-life experience decreases druginduced reinstatement of morphine CPP in adulthood via microglial-specific epigenetic programming of anti-inflammatory IL-10 expression. J Neurosci. 2011;31:17835-47.

120. Correa F, Hernangomez-Herrero M, Mestre L, Loria F, Docagne F, Guaza C. The endocannabinoid anandamide downregulates IL-23 and IL-12 subunits in a viral model of multiple sclerosis: evidence for a cross-talk between IL-12p70/IL-23 axis and IL-10 in microglial cells. Brain Behav Immun. $2011 ; 25: 736-49$

121. Liu J, Zhao X, Cao J, Xue Q, Feng X, Liu X, Zhang F, Yu B. Differential roles of PKA and Epac on the production of cytokines in the endotoxinstimulated primary cultured microglia. J Mol Neurosci. 2011;45:186-93.

122. Li YN, Qin XJ, Kuang F, Wu R, Duan XL, Ju G, Wang BR. Alterations of Fc gamma receptor I and Toll-like receptor 4 mediate the antiinflammatory actions of microglia and astrocytes after adrenaline-induced blood-brain barrier opening in rats. J Neurosci Res. 2008;86:3556-65.

123. Yang S, Gao L, Lu F, Wang B, Gao F, Zhu G, Cai Z, Lai J, Yang Q. Transcription factor myocyte enhancer factor $2 \mathrm{D}$ regulates interleukin-10 production in microglia to protect neuronal cells from inflammationinduced death. J Neuroinflammation. 2015:12:33.

124. Ivanov P, Anderson P. Post-transcriptional regulatory networks in immunity. Immunol Rev. 2013:253:253-72.

125. Brown PN, Yin H. PNA-based microRNA inhibitors elicit anti-inflammatory effects in microglia cells. Chem Commun (Camb). 2013;49:4415-7.

126. Hutchison ER, Kawamoto EM, Taub DD, Lal A, Abdelmohsen K, Zhang Y, Wood 3rd WH, Lehrmann E, Camandola S, Becker KG, et al. Evidence for miR-181 involvement in neuroinflammatory responses of astrocytes. Glia. 2013;61:1018-28.

127. Green HF, Nolan YM. GSK-3 mediates the release of IL-1 beta, TNF-alpha and IL-10 from cortical glia. Neurochem Int. 2012;61:666-71.

128. Ajmone-Cat MA, D'Urso MC, di Blasio G, Brignone MS, De Simone R, Minghetti L. Glycogen synthase kinase 3 is part of the molecular machinery regulating the adaptive response to LPS stimulation in microglial cells. Brain Behav Immun. 2016;55:225-35.

\section{Submit your next manuscript to BioMed Central and we will help you at every step:}

- We accept pre-submission inquiries

- Our selector tool helps you to find the most relevant journal

- We provide round the clock customer support

- Convenient online submission

- Thorough peer review

- Inclusion in PubMed and all major indexing services

- Maximum visibility for your research

Submit your manuscript at www.biomedcentral.com/submit
) Biomed Central 